
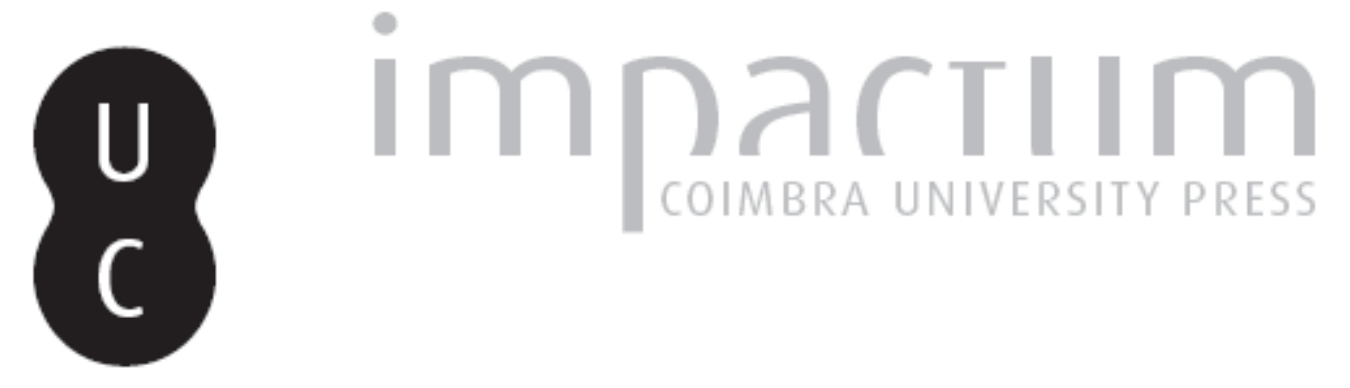

\title{
Um pequeno (mas fundamental) livro sobre montanhas
}

\section{Autor(es): $\quad$ Rebelo, Fernando}

Publicado por: Associação Portuguesa de Riscos, Prevenção e Segurança

URL persistente:

URI:http://hdl.handle.net/10316.2/40078

DOI:

DOI:https://doi.org/10.14195/1647-7723_10_9

Accessed : $\quad$ 26-Apr-2023 15:24:01

A navegação consulta e descarregamento dos títulos inseridos nas Bibliotecas Digitais UC Digitalis, UC Pombalina e UC Impactum, pressupõem a aceitação plena e sem reservas dos Termos e Condições de Uso destas Bibliotecas Digitais, disponíveis em https://digitalis.uc.pt/pt-pt/termos.

Conforme exposto nos referidos Termos e Condições de Uso, o descarregamento de títulos de acesso restrito requer uma licença válida de autorização devendo o utilizador aceder ao(s) documento(s) a partir de um endereço de IP da instituição detentora da supramencionada licença.

Ao utilizador é apenas permitido o descarregamento para uso pessoal, pelo que o emprego do(s) título(s) descarregado(s) para outro fim, designadamente comercial, carece de autorização do respetivo autor ou editor da obra.

Na medida em que todas as obras da UC Digitalis se encontram protegidas pelo Código do Direito de Autor e Direitos Conexos e demais legislação aplicável, toda a cópia, parcial ou total, deste documento, nos casos em que é legalmente admitida, deverá conter ou fazer-se acompanhar por este aviso.

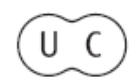




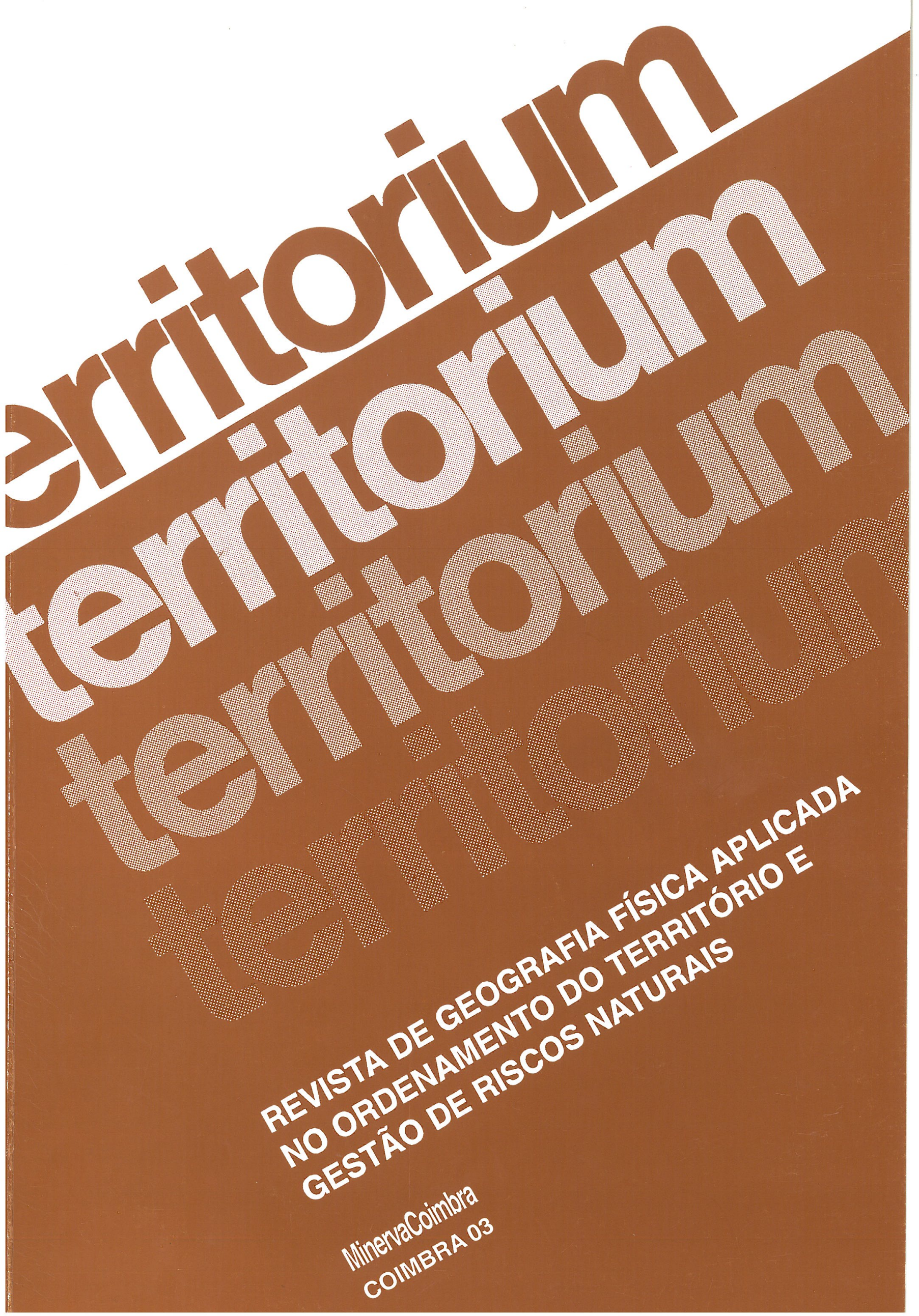




\section{Um pequeno (mas fundamental) livro sobre montanhas}

\section{Fernando Rebelo}

Les montagnes. Discours et enjeux géographiques (Liège, SEDES, 2001, 141 p.) é um pequeno livro que se nos afigura de grande importância no contex to do estudo das montanhas, particularmente em termos de riscos. Coordenado pela Prof ${ }^{a}$ Yvette VEYRET, da Universidade de Paris $X$, Nanterre, que escreve a introdução e mais dois capítulos, tem ainda como autores Bernard Debarbieux, François Bart e Marie Claude Cassé-Castells.

O primeiro destes três autores, nos dois capítulos que escreve, discute se a montanha é um objecto geográfico e apresenta-nos as representações e as construções culturais que se fazem sobre as montanhas. O segundo, igualmente em dois capítulos, discute a questão da marginalidade e da integração destes espaços, relacionando-os com a problemática da sua densidade demográfica; curiosamente, refere-se também às montanhas dos países tropicais com um bom conjunto de exemplos. O terceiro intitula o capítulo que lhe coube com uma pergunta: "como abordar a questão da montanha hoje nos países industrializados da Europa ocidental?"

Com o título de "mobilidades e descontinuidades físicas", Yvette VEYRET oferece-nos um capítulo rico em exemplos, mas sintético no essencial, com referências bibliográficas muito importantes para quem quiser maior profundidade; a mobilidade tectónica e climática é tratada a diversas escalas, como também o escalonamento climático é apresentado na sua diversidade consoante as áreas montanhosas se situam em zonas morfoclimáticas diferentes. Trata-se da base necessária para o capítulo seguinte: "riscos e gestão do ambiente". A autora gosta de dar exemplos concretos de manifestação de crises; desta vez recorre a casos históricos, recolhidos tanto na Idade Média, como nos séculos XVIII ou XIX, antes de se referir a casos actuais e de todos eles retirar as devidas consequências. Por isso, sublinha os aspectos mais relevantes da protecção à montanha e das formas variadas que reveste pelo mundo.

No seu conjunto, Les montagnes. Discours et enjeux géographiques é um livro que faz pensar, mas que também dá a geógrafos físicos e humanos, tal como ao público em geral, numerosos exemplos do que pode acontecer numa montanha, seja porque já aconteceu no passado mais ou menos distante, seja porque, com os dados de que se dispõe, há a hipótese de vir a acontecer. A consciência do risco e a percepção do perigo em áreas de montanha ficam mais fortalecidas depois de ler este livro.

\section{A propósito de um notável trabalho sobre riscos naturais desenvolvido na Suíça ao longo dos anos 90}

\section{Fernando Rebelo}

Climat et risques naturels-LaSuisse enmowement, de Stephan BADER e Pierre KUNZ (vdf, Zurich; georg, Genève, 1998, 312 p.), é, ao mesmo tempo, um Relatório científico final de um Programa nacional de investigação sobre riscos naturais, desenvolvido ao longo dos anos 90 , e um verdadeiro tratado sobre riscos naturais relacionados com o clima.

Após uma introdução sobre o Programme National de Recherche que esteve na sua origem (PNR 31) e que se intitulava, como era de bom tom na época, "Changements climatiques et Catastrophes naturelles", o trabalho aparece dividido em cinco partes e termina com um texto conclusivo.
Curiosamente, o título da primeira parte corresponde a uma interrogação: "Changement climatique? Radioscopie du climat de la Suisse". É da autoria de S. BADER e tem por primeiro capítulo uma frase que podíamos de imediato subscrever - "CClimat' a toujours été synonyme de 'changement'". Habituámo-nos de tal maneira a falar em valores médios que nos convencemos de que a média é normal e tudo o que fugir à média nãoé normal e a curto ou médio prazo terá consequências catastróficas... O exagero dos não geógrafos que tratam destes temas tende a influenciar os geógrafos, principalmente os menos preparados ou, talvez, os menos críticos. Claro que "o clima é sensível a 